\title{
A geografia da alimentação no contexto da pandemia: repensando os sistemas alimentares para o sustento dos corpos e do planeta ${ }^{1}$
}

\section{The geography of food in the context of the pandemic: rethinking food} systems to sustain bodies and the planet

PATRÍCIA PONTE

Doutora em Geografia e Professora da Licenciatura em Geografia do Instituto Federal da Bahia (IFBA - Campus Salvador). patriciaponte@ifba.edu.br

\section{RESUMO}

A crise proveniente da pandemia do novo coronavírus vem tornando ainda mais urgente a necessidade de repensarmos práticas individuais e sociais e as formas como elas afetam o planeta. Uma dessas práticas diz respeito à nossa alimentação, cada vez mais dependente de um sistema alimentar industrial que aprofunda problemas socioeconômicos, ambientais e sanitários - como as pandemias. Aliando a análise de aspectos estruturais às dimensões culturais e interseccionais que influenciam os hábitos alimentares contemporâneos, visamos com este artigo refletir sobre os impactos das nossas escolhas alimentares sobre o meio ambiente e os diferentes grupos populacionais, buscando uma geografia da alimentação que proponha/construa caminhos alternativos para a redução desses impactos e para a transformação dos atuais sistemas alimentares.

Palavras-chave: Geografia da alimentação. Pandemia. Sistema alimentar. Meio ambiente. Grupos populacionais.

\begin{abstract}
The crisis due to the pandemic of the new coronavirus is making the need to rethink individual and social practices and the ways they affect the planet even more urgent. One of these practices concerns our food, which is increasingly dependent on an industrial food system that deepens socioeconomic, environmental and health problems - such as pandemics. Combining the analysis of structural aspects with the cultural and intersectional dimensions that influence contemporary eating habits, with this article we aim to reflect on the impacts of our food choices on the environment and different population groups, seeking a geography of food that proposes / builds alternative paths to reduce these impacts and transform current food systems.
\end{abstract}

Keywords: Geography of food. Pandemic. Food system. Environment. Population groups.

\section{INTRODUÇÃO: OS DOIS LADOS DA BALANÇA ALIMENTAR}

Falar de alimentação é falar de um fenômeno multidimensional, material e simbólico, fundamental não apenas para a sobrevivência, mas para a existência dos humanos em e enquanto sociedades. Poucas coisas são tão universais como a comida, da mesma maneira como é diversa e particular a alimentação dos povos e dos sujeitos. A origem da palavra alimento está ligada ao verbo alere, do latim, cujo significado é desenvolver, animar, e os significados da alimentação perpassam pelas ideias de sustento, manutenção e abastecimento. Sendo assim, podemos dizer que os alimentos mantêm e sustentam além dos nossos corpos, também nossas culturas, as relações-interpessoais e o planeta como um todo.

\footnotetext{
${ }^{1}$ Artigo recebido em: 27.09.2020 e aprovado em: 30.10.2020.
} 
Rev. Interd. em Cult. e Soc. (RICS), São Luís, v. 6, n. 2, p. 174-194, jul./dez. 2020

ISSN eletrônico: $2447-6498$

Falar de alimentação diz respeito a todos(as) e é sempre, pois, instigante, pertinente e complexo, pela diversidade de abordagens que podem ser seguidas. Mas, nesse momento, talvez outro adjetivo se sobreponha aos demais: falar de alimentação é urgente. A urgência, qualidade que já acompanha o tema alimentação - ou, mais especificamente, a falta dela - nos diferentes estudos sobre a fome no mundo, pode ser aplicada agora quando nos debruçamos sobre os excessos da produção e do consumo de certos alimentos nas últimas décadas. Falta e excesso, cada um em um lado da balança alimentar, mas partes do mesmo problema.

Nos anos 1940, a denúncia de Josué de Castro $^{2}$ era da fome como produto do subdesenvolvimento e das desigualdades do sistema capitalista, mas Castro não pôde ver em vida o patamar ao qual chegaria a produção industrial de alimentos e todas as transformações que ela viria provocar no meio ambiente e nos hábitos alimentares das pessoas em todo o mundo. De acordo com diferentes estudos científicos e relatórios de organizações internacionais, temos atualmente um cenário alimentar mundial no qual mais pessoas morrem por doenças relacionadas ao consumo excessivo de certos alimentos do que por fome ${ }^{3}$ (ainda que a fome tenha aumentado no mundo nos últimos dois anos [DW, 2019]). Da mesma forma, o mais abrangente estudo epidemiológico mundial, Global Burden Diseace, afirma que a má dieta alimentar é o fator de risco responsável pelo maior número de mortes no mundo (GBD, 2019). Recentes estimativas da Organização das Nações Unidas para Alimentação e Agricultura (FAO) indicam que o número de pessoas obesas no mundo (em torno de 830 milhões) já superou o número de pessoas que sofrem de fome. Hoje, portanto, há mais obesos do que famintos no mundo (NAÇÕES UNIDAS BRASIL, 2019).

Alimentar significa sustentar, mas o que vemos hoje é um número cada vez maior de pessoas que morrem em decorrência do que comem. Da mesma forma, as paisagens estão morrendo em decorrência dos usos que lhe são atribuídos com a justificativa de alimentar as pessoas e as alterações climáticas em escala global têm, dentre suas causas, a produção de alimentos dentro de um sistema industrial. Sobrepondo-se a esse contexto por si só alarmante, no momento em que esse artigo é escrito, o planeta está vivenciando a sua maior crise sanitária e, de forma talvez não tão difundida, as causas e raízes dessa pandemia também se relacionam com a alimentação.

Dessa maneira, falar de pandemias, meio ambiente e saúde pública passa pela compreensão de como nos alimentamos. Tais correlações vêm se aprofundando de forma

\footnotetext{
${ }^{2}$ Em sua obra clássica Geografia da Fome, publicada originalmente em 1946.

${ }^{3}$ WHO. Global Health Estimates 2016: Disease burden by Cause, Age, Sex, by Country and by Region, 2000-2016. Geneva, World Health Organization; 2018.
} 
Rev. Interd. em Cult. e Soc. (RICS), São Luís, v. 6, n. 2, p. 174-194, jul./dez. 2020

ISSN eletrônico: $2447-6498$

recente, em especial nas últimas cinco décadas, e, para entendê-las, é necessário que analisemos a predominância do sistema alimentar industrial ${ }^{4}$ sobre os sistemas alimentares tradicionais/ sustentáveis como ponto central da questão, mas considerando também outras dimensões que tangem os hábitos alimentares, em especial os aspectos culturais e subjetivos e as abordagens interseccionais, que corporificam os sujeitos que se alimentam.

Aliando essas diferentes escalas e abordagens do fenômeno alimentar contemporâneo, acreditamos ter mais ferramentas para responder as seguintes questões que consideramos relevantes: como se articulam política e economicamente os diferentes sistemas alimentares e de que forma eles podem sustentar ou adoecer as pessoas e o planeta? Como os hábitos alimentares vem sendo transformados no mundo e de que forma os diferentes grupos populacionais vivenciam essas mudanças? E o mais importante: o que podemos fazer para transformar esse cenário a partir de nossas práticas cotidianas individuais e coletivas de alimentação? Essas são questões que consideramos não apenas pertinentes, mas agora - em decorrência da pandemia que vivemos - urgentes de serem pensadas pela geografia e pelas demais ciências humanas e sociais.

\section{PANDEMIAS E ALIMENTAÇÃO}

A maioria das novas doenças que surgiram em humanos nas últimas décadas têm origem animal e estão relacionadas à busca humana por mais alimentos de origem animal. Essa é a premissa inicial do relatório da FAO "World Livestock - Changing disease landscapes", publicado no ano de 2013. Segundo o estudo, mais de $70 \%$ das doenças humanas são originadas em animais, através de atividades como agricultura perto de florestas, desmatamento e extração de madeira, caça e/ou preparo de carne de animais selvagens e criação de animais para consumo (agricultura animal).

Ainda segundo o relatório, a agricultura animal é a atividade humana que mais utiliza recursos terrestres $(\mathrm{FAO}, 2013$, p.2), e a centralidade que essa atividade passou a ocupar na produção alimentar do mundo nas últimas décadas se deve não apenas ao crescimento absoluto da população mundial, mas, especialmente, à transição das populações das áreas rurais para as cidades e ao aumento da renda média dessas populações. Esses fatores promoveram a criação de novos hábitos alimentares, e os setores de produção alimentícia

\footnotetext{
4 Os sistemas alimentares compreendem todos os elementos (ambiente, pessoas, insumos, processos, infraestruturas, instituições etc.) e atividades relacionadas à produção, transformação, distribuição, preparação e consumo de alimentos (HLPE, 2014, p. 29). De acordo com Mabel Gracia Arnaiz, o sistema alimentar industrial baseia-se na intensificação da produção agrícola e pecuária, orientação da política de oferta e demanda de determinados alimentos, concentração dos negócios em poucas empresas, ampliação e especialização por meio das redes comerciais cada vez mais onipresentes e na internacionalização da alimentação (2005, p. 147).
} 
Rev. Interd. em Cult. e Soc. (RICS), São Luís, v. 6, n. 2, p. 174-194, jul./dez. 2020

ISSN eletrônico: $2447-6498$

mudaram "seu foco principal do fornecimento de cereais como produtos básicos para o fornecimento de uma dieta cada vez mais rica em proteínas baseada em produtos animais e de pesca"5 (FAO, 2013, p. 2).

O rápido crescimento da criação industrial de animais (e as condições insalubres em que muitas vezes são feitas) vem provocando ameaças à saúde pública, pondo em risco não apenas a segurança dos alimentos, mas também aumentando os riscos de surgimento de doenças zoonóticas e de pandemias (FAO, 2013, p. 3). Esse risco é de amplo conhecimento dos grupos de cientistas e de organizações internacionais de saúde como a OMS, que, em relatórios da década de 2000 (publicados logo após o surto da síndrome respiratória aguda grave - $\mathrm{SARS}^{6}$, em 2003) alertavam os países sobre a iminência de uma nova pandemia e seus possíveis efeitos sanitários e econômicos:

O recente surto de gripe aviária na Ásia serve para nos lembrar que outra pandemia de gripe é inevitável [...] E ela está vindo. E quando acontecer, nós sabemos que não teremos remédios, vacinas, profissionais de saúde e hospitais suficientes ${ }^{7}$ (WHO, 2004, p. 317)

De fato, apenas cinco anos após essa publicação, a pandemia de gripe suína teve início, causada pela disseminação do vírus influenza H1N1 em 2009. Quatro meses depois de ser descoberto, o vírus já havia se disseminado pelo planeta e chegado a 114 países. Estudos científicos estimam hoje que de $11 \%$ a $24 \%$ da população global na época - entre 700 milhões e 1,7 bilhão de pessoas - tenham contraído o H1N1. A princípio, a OMS apontou que cerca de 18 mil pessoas morreram por causa do vírus, mas, em um estudo posterior, reviu esse total para 200 mil mortes (BARIFOUSE, 2020).

Após o fim da pandemia de gripe suína, declarado 14 meses após seu início, outros surtos de coronavírus foram identificados pelo mundo, como o da síndrome respiratória do Oriente Médio, registrada na Península Arábica e em países do Oriente Próximo, Norte da África e Europa Ocidental (FAO, 2013, p. 56). O receio e o acompanhamento em forma de alerta para o surgimento de uma nova pandemia continuavam por parte da OMS, que em 2019 publicou um programa de prevenção, controle e preparo para uma próxima pandemia de influenza, intitulado Global Influenza Strategy for 2019-2030. O programa tinha em conta o

\footnotetext{
${ }^{5}$ Tradução livre do original: « world food and agriculture has shifted its main focus from the supply of cereals as staples to providing an increasingly protein-rich diet based on livestock and fisheries products »

${ }^{6} \mathrm{O}$ surto de SARS começou em novembro de 2002 na província de Guangdong, na China, e em poucas semanas se espalhou para 29 países em cinco continentes, infectando mais de 8.000 pessoas e resultando em 774 mortes (WALLACE, 2020)

${ }^{7}$ Tradução livre do original: "The recent avian influenza outbreaks in Asia serve as stark reminders that another influenza pandemic is inevitable [...] It is coming. And when it happens, we also know that we are unlikely to have enough drugs, vaccines, health care workers and hospital capacity to cope in an ideal way”.
} 
aumento dos fluxos globais e da urbanização, que causaria uma disseminação ainda mais rápida da doença e impactos maiores do que os das pandemias anteriores. Apenas alguns meses depois, no mesmo ano de 2019, a ameaça se concretizou com a descoberta do novo coronavírus (Sars-Cov-2), na província de Wuhan, na China.

Todas essas pandemias de gripe e as que as antecederam, como a gripe espanhola em 1918, a gripe asiática em 1957, a gripe de Hong Kong em 1968, têm em comum a origem no contato entre homens e animais, sejam de criação ou selvagens. A origem das gripes suínas remonta à pandemia de gripe espanhola em 1918-1919, quando a gripe foi observada nos suínos pela primeira vez e, desde então, o vírus $\mathrm{H} 1 \mathrm{~N} 1$ passou a circular em porcos. O surgimento da SARS em seres humanos foi originado do consumo/ manuseio de civetas de palma, que têm se tornado popular como alimento exótico desde o final da década de 1980. As características da síndrome respiratória do Oriente Médio sugerem que esse coronavírus pode ter atingido os seres humanos através do camelo como hospedeiro amplificador (FAO, 2013, p. $49-56)$.

Apesar de o contato entre homens e animais ser comum na história da humanidade, as formas como esse contato vem ocorrendo nas últimas décadas são diferentes: "Estamos mais em contato com os animais do que nunca", assim como os rebanhos e a vida selvagem estão mais em contato (FAO, 2013, p. IX). As causas e as consequências dessa atual interface com os animais são assim expostas pela FAO:

a população humana em expansão está habitando mais áreas selvagens, enquanto se torna cada vez mais dependente de animais para alimentação. As densidades dos animais estão mudando e os sistemas de produção estão impactando uns aos outros de novas maneiras. O comércio de gado está em ascensão e as mudanças climáticas estão criando novas oportunidades para o desenvolvimento de doenças animais. A dinâmica da cadeia alimentar está permitindo que mais doenças se desenvolvam mais rapidamente, e a degradação dos habitats naturais está reduzindo os mecanismos naturais de enfrentamento ${ }^{8}$. (2013, p. IX)

No caso da atual pandemia de Covid-19, o surgimento do novo coronavírus ocorreu na cidade de Wuhan, na China, em um dos chamados mercado vivos (wet markets), onde se comercializam diferentes espécies de animais selvagens. Esses mercados surgiram na China na década de 1970, em decorrência das ondas de fome que mataram milhões de pessoas nas áreas rurais do país. Esses ambientes são propícios ao surgimento de novos vírus e à

\footnotetext{
${ }^{8}$ Tradução livre do original: "our expanding human population is inhabiting more wilderness while becoming ever more reliant on animals for food. Livestock densities are changing, and production systems are impacting each other in new ways. Livestock-related trade is on the rise, and climate change is creating new opportunities for animal diseases to thrive. Food chain dynamics are enabling more diseases to develop more quickly, and the degradation of natural habitats is reducing natural coping mechanisms".
} 
Rev. Interd. em Cult. e Soc. (RICS), São Luís, v. 6, n. 2, p. 174-194, jul./dez. 2020

ISSN eletrônico: $2447-6498$

contaminação humana, devido às condições em que os animais são expostos, geralmente vivos e amontoados, em contato com secreções de espécies diferentes. Apesar de, até o presente momento não estar totalmente comprovado, estudos apontam que o Sars-Cov-2 se originou da mistura de secreções de morcegos e pangolins, e que este último atuou como intermediário, ou seja, foi infectado por morcegos e transmitiu o vírus ao homem (XIAO, K., ZHAI, J., FENG, Y. et al., 2020).

Em uma análise superficial - e mais cômoda, para alguns -, poderíamos atribuir as recentes epidemias e pandemias de gripes a hábitos "exóticos" de consumo de animais silvestres, inexistentes nas sociedades ocidentais, o que poderia incorrer em julgamentos xenófobos e atribuições de culpa ao "outro", à "outra" cultura, ao "outro" hábito alimentar. No entanto, é a criação industrial de rebanhos bovinos, suínos e de aves (comuns aos hábitos alimentares ocidentais) o principal vetor do surgimento de doenças zoonóticas (PAIM, C. S. e ALONSO, W., 2020), além de contribuir para a resistência aos antibióticos, utilizados de forma indiscriminada nessas criações (DUTKIEWICZ, TAYLOR e VETTESE, 2020).

Apesar das evidências e dos riscos do surgimento de novas doenças zoonóticas ${ }^{9}$, pouco parece estar sendo feito pelos organismos internacionais no sentido de se repensar o sistema alimentar global. Em um ensaio publicado no American Journal of Public Health, os autores chamam atenção para o fato de que "mudar a maneira como os humanos tratam os animais [...] está amplamente fora do radar como uma medida preventiva significativa"10. Da mesma forma, em 2016, o Programa de Meio Ambiente do Reino Unido alertou que a "revolução dos rebanhos" (livestock revolution) era um desastre zoonótico esperando para acontecer (DUTKIEWICZ, TAYLOR e VETTESE, 2020).

É preciso considerar que, mesmo fora de contextos extremos como os das pandemias, a criação industrial de animais provoca uma série de danos para o meio ambiente, oferecendo outros riscos à vida humana. Esses danos podem ser menos imediatos e por isso menos diretamente percebidos do que os de uma pandemia, mas, da forma e na escala em que a produção agroindustrial vem funcionando atualmente (e se mantida a previsão de crescimento), a tendência é a de que esses impactos se agravem severamente, afetando as condições de vida e sustento do planeta dentro de poucas décadas.

\footnotetext{
9. Um alerta emitido pela OMS informou que 26 casos de infecção por vírus influenza $A(H 1 N 2) v$ foram registrados desde 2005. Um dos casos mais recentes foi identificado em uma paciente da cidade de Ibiporã, no Paraná, por pesquisadores da FIOCRUZ, em julho de 2020.(MENEZEZ, 2020)

${ }^{10}$ Tradução livre do original: "changing the way humans treat animals [...] is largely off the radar as a significant preventive measure."
} 
Rev. Interd. em Cult. e Soc. (RICS), São Luís, v. 6, n. 2, p. 174-194, jul./dez. 2020

ISSN eletrônico: $2447-6498$

\section{UM SISTEMA ALIMENTAR INSUSTENTÁVEL PARA O PLANETA}

De acordo com um estudo publicado pela revista Science em 2018, estamos consumindo mais produtos de origem animal para alimentação do que nunca, tanto em termos absolutos quanto per capta (GODFRAY et al, 2018, p. 1). Se considerarmos o período compreendido entre os anos 1960 até hoje, enquanto o número de pessoas no planeta dobrou, a quantidade de carne que comemos aumentou quase cinco vezes - de 71 milhões de toneladas produzidas no início dos anos 1960 para mais de 342 milhões em 2018 (OUR WORLD IN DATA, 2020).

Atualmente, a maior parte dessa demanda crescente vem de países de renda média - e particularmente da China, que se tornou o maior consumidor mundial de carne à medida que sua economia crescia. No entanto, ao considerarmos o consumo per capta dos países, são os países de renda mais alta, de forma geral, os maiores consumidores de carne no mundo. De acordo com a FAO, como média global, o consumo per capta de carne em 2014 era de $43 \mathrm{~kg}$ ao ano (um aumento de aproximadamente $20 \mathrm{~kg}$ desde 1961). Para termos uma ideia da espacialidade e desigualdades do consumo de carne, enquanto nos Estados Unidos uma pessoa consumia em média, em 2017, 124,7 kg de carne por ano, na Austrália foram $121 \mathrm{~kg}$, na Argentina, 109 kg, e no Brasil, 99,8 kg. Já a média de consumo no continente africano é de $20 \mathrm{~kg}$ por pessoa ao ano, sendo que em alguns países o consumo é de até $10 \mathrm{~kg} / \mathrm{ano}$ (OUR WORLD IN DATA, 2020). Além da mudança na quantidade de carne consumida, houve nesse período grandes mudanças nos tipos de carne consumidos em muitas regiões, em especial com o aumento do consumo de carne frango e de porco. Além disso, uma maior fração da carne consumida hoje é processada antes da compra (GODFRAY et al, 2018, p. 1).

Segundo os dados mais recentes da FAO, são abatidos por ano para consumo cerca de 78,4 bilhões de animais, sendo mais de 68 bilhões de frangos, 302 milhões de bovinos e 1,4 bilhões de porcos, para citar os mais comuns ${ }^{11}$ (FAOSTAT, 2018). Não é difícil imaginar que essa enorme quantidade de animais demanda uma quantidade igualmente enorme de recursos (como terra, água, alimento e energia), além de produzir uma expressiva quantidade de dejetos e de emitir, direta e indiretamente, poluentes que serão dispersados no solo, no ar e na água. Se a criação industrial de animais já oferece pressão sobre os recursos atualmente, caso a previsão de aumento de consumo global de carne se confirme - aumento de $76 \%$ do consumo total em 2050 (GODFRAY et al, 2018, p.1) -, ela não só será insustentável, como se tornará inviável nas próximas décadas.

\footnotetext{
${ }^{11}$ A FAO não faz o cálculo do número de peixes e demais animais aquáticos abatidos.
} 
Rev. Interd. em Cult. e Soc. (RICS), São Luís, v. 6, n. 2, p. 174-194, jul./dez. 2020

ISSN eletrônico: $2447-6498$

Atualmente, um quarto da superfície terrestre é usado para pastagem de ruminantes, e um terço da terra arável global é usada para cultivar ração para gado - o que representa $40 \%$ da produção total de cereais (FAO, 2013, p. 2). A pecuária requer muito mais terra do que outras formas de agricultura, fato que impulsiona o desmatamento. A maior população de gado do mundo está no Brasil, onde o número quadruplicou em cinquenta anos e levou à destruição de vastas áreas da floresta amazônica. A conversão de habitats naturais em pastagens e a destinação de terras cultiváveis para produção de grãos para consumo de animais são as maiores ações indiretas por meio das quais a produção de carne afeta a biodiversidade ${ }^{12}$.

Dessa maneira, as florestas são derrubadas ou queimadas para a implantação de pastagens e convertidas em terras aráveis para atender a demanda por ração animal, o que tem como resultado um sistema de produção de alimentos de extrema ineficiência. De acordo com dados publicados pelo World Economic Forum, para alimentar os animais criados para consumo, são usadas aproximadamente dez vezes mais calorias do que as contidas em sua carne (THORNTON, 2019). Cada caloria de carne produzida requer o uso de áreas de cultivo pelo menos seis vezes maiores do que o necessário para produzir uma caloria com cultivos vegetais como batata, milho e arroz; e, no caso da produção de carne bovina, a área necessária pode ser mais de 100 vezes maior (GODFRAY et al, 2018, p. 7).

Outro aspecto ambiental afetado pela produção de carne está relacionado à emissão de gases do efeito estufa, responsáveis pelo aquecimento global. A produção de carne resulta nas emissões dos três gases mais importantes - dióxido de carbono $(\mathrm{CO} 2)$, metano e nitrogênio (N2O) - e é a maior fonte emissora de metano. Usando a medição de equivalentes de CO2, a produção animal é responsável por $15 \%$ de todas as emissões humanas (GODFRAY et al, 2018 , p. 4), emitindo mais que o dobro de gases do efeito estufa em relação a todos os demais produtos agrícolas.

Quando consideramos o uso da água, a produção de animais também tem um impacto relevante. A agricultura utiliza mais água doce do que qualquer outra atividade humana e quase 1/3 é para o gado (GODFRAY et al, 2018, p. 1). Além disso, quando consideramos indicadores como a pegada hídrica (quantidade de água potável utilizada em toda a cadeia de produção de um alimento ou mercadoria), que, no caso da produção de carne bovina, é de 15.4 mil litros por quilo (média global), observamos índices de ineficiência na comparação

${ }^{12}$ A estimativa é de que $71 \%$ da conversão da floresta tropical na América do Sul tenha sido motivada pela criação de gado e outros, incluindo soja para alimentação animal (V. De SY et al., 2015, apud. GODFRAY et al, 2018, p. 5) 
Rev. Interd. em Cult. e Soc. (RICS), São Luís, v. 6, n. 2, p. 174-194, jul./dez. 2020

ISSN eletrônico: $2447-6498$

com outros produtos agrícolas, como arroz $(3.400 \mathrm{~L} \mathrm{~kg})$, milho $(900 \mathrm{~L} \mathrm{~kg})$ e batata $(250 \mathrm{~L} \mathrm{~kg})$ (DA SILVA, V. P. et al, 2012). O mesmo se aplica ao analisarmos outros critérios como a pegada hídrica por caloria (vinte vezes maior que a dos cereais e raízes) e a pegada hídrica por grama de proteína. Do ponto de vista dos recursos de água doce, é mais eficiente obter calorias, proteínas e gorduras através de produtos agrícolas do que de produtos animais ${ }^{13}$.

Segundo a FAO, dentre as atividades primárias, a agricultura e a pecuária são as maiores fontes de poluição de mananciais e corpos d'água (AGENCIA EFE, 2018), a primeira devido ao escoamento de fertilizantes e pesticidas, e a segunda pela produção de dejetos nas fazendas industriais e abatedouros. No sistema de criação intensiva, predominante nas fazendas e granjas industriais, a enorme quantidade de animais confinados por metro quadrado $^{14}$ é responsável por uma expressiva produção diária de desejos: para citarmos apenas um exemplo, no estado de Santa Catarina, um plantel de aproximadamente 8,42 milhões de suínos produz diariamente um volume aproximado de 72,41 milhões de litros de dejetos, grande parte lançado no meio ambiente (SILVA CL, 2012).

A falta de tratamento de dejetos nas fazendas industriais provoca contaminações múltiplas: quando lançados em terra, os dejetos infiltram-se no solo, contaminando lençóis freáticos, reservatórios e aquíferos; quando despejados na água, a contaminação atinge diretamente os organismos aquáticos, podendo provocar a morte de milhões de peixes ${ }^{15}$. Há ainda a contaminação pelo ar, quando os dejetos são borrifados nos campos das propriedades. Esses dejetos contêm diversas toxinas (que podem dar origem a mais de cem patógenos microbianos ${ }^{16}$ ) e resíduos de hormônios e antibióticos administrados aos animais ${ }^{17}$, que contaminam a água subterrânea, superficial e encanada.

Os impactos dessa forma de produção se fazem sentir não apenas no meio ambiente, mas, sim, diretamente na vida das pessoas. No estado da Carolina do Norte, nos Estados Unidos, as populações vizinhas às granjas suínas além de terem suas propriedades desvalorizadas devido aos intensos odores dos dejetos borrifados por essas fazendas, apresentam diversos problemas de saúde decorrentes da poluição e que incidem inclusive em

\footnotetext{
${ }^{13}$ M.M. MEKONNEN e A.Y. HOEKSTRA. The green, blue and grey water footprint of farm animals and animal products. UNESCO-IHE Institute for Water Education, 2010.

${ }^{14}$ No Paraná, apenas um (1) barracão de uma granja é capaz de abrigar 50 mil frangos. É o modelo de criação “4,0" que visa intensificar a produtividades do setor agropecuário no Brasil. (GLOBO RURAL, 2019)

${ }^{15}$ DOVE, 2018.

16 TIETZ, 2005.

${ }^{17}$ Que podem ocasionar a ocorrência de superbactérias como a MSRA, reportadas em fazendeiros e moradores de comunidades vizinhas às granjas industriais nos Estados Unidos. (KRISTOF, 2009)
} 
Rev. Interd. em Cult. e Soc. (RICS), São Luís, v. 6, n. 2, p. 174-194, jul./dez. 2020 ISSN eletrônico: $2447-6498$

uma expectativa de vida menor do que a média do estado ${ }^{18}$. Em sua maioria, os grupos populacionais vizinhos às granjas industriais são pobres e não-brancos ${ }^{19}$.

As fazendas industriais de suínos são bastante exemplares dos impactos da criação intensiva de animais para o meio ambiente e para as pessoas, além de exemplos do imenso poder político e econômico que essas corporações detêm. O poder de reconfigurar formas de produção e relações sociais se expressa também na reconfiguração das paisagens no entorno dessas granjas: ao lado dos galpões, são construídas "lagoas" (que adquirem uma cor rosa, por isso são chamadas de pink lagoons) cuja extensão pode chegar à 11 mil metros quadrados e 9 metros de profundidade, e para as quais os dejetos são bombeados. De forma recorrente, essas lagoas se rompem durante a ocorrência de furacões, provocando extensos vazamentos e, consequentemente, graves danos ambientais ${ }^{20}$.

Figura 01: Pink lagoons e as granjas suínas (Carolina do Norte, Estados Unidos)

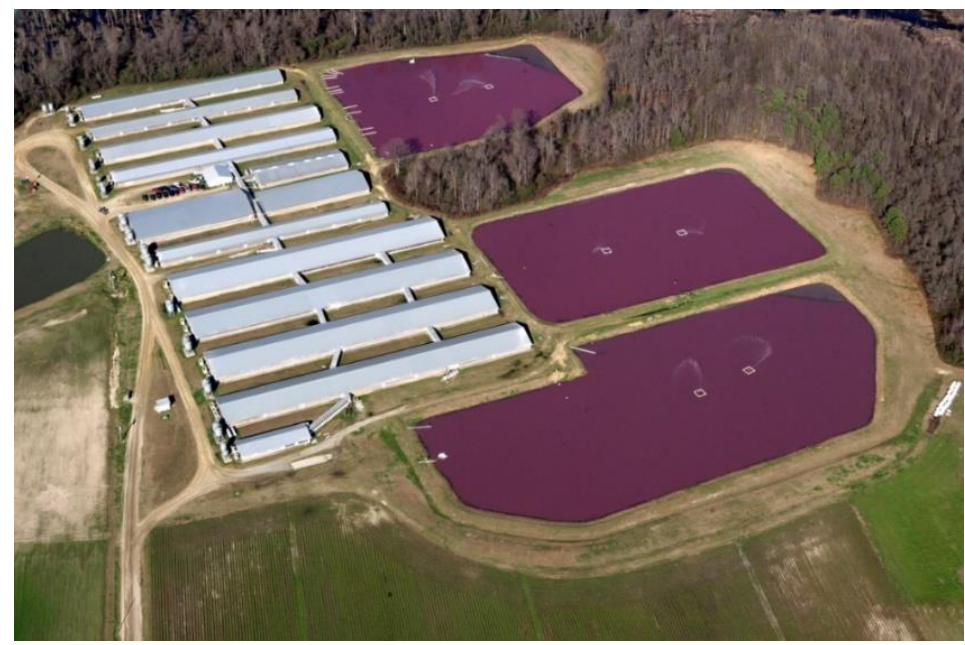

Fonte: https://civileats.com/2018/06/26/in-north-carolina-new-pollution-allegations-add-to-residents-woes-overfactory-farms/

Mesmo diante da mobilização de parte da sociedade pedindo o fim dessas estruturas de produção, as empresas continuam atuando nos mesmos moldes e expandindo suas operações devido a flexibilizações nas legislações locais a seu favor. O lobby da indústria alimentícia e da agropecuária está presente em muitos países (como vemos com a "bancada

\footnotetext{
${ }^{18}$ Um estudo publicado no North Carolina Medical Journal demonstrou que os moradores próximos às operações de animais industriais tinham taxas mais altas de mortalidade por todas as causas, mortalidade infantil, mortalidade por anemia, doença renal, tuberculose e septicemia, além de taxas mais altas de visitas às urgências. (DOVE, 2018)

${ }^{19}$ DOVE, 2018

${ }^{20}$ Em 1995, a SmithField, maior corporação mundial no ramo da suinocultura, provocou o vazamento de mais de 75 milhões de litros de dejetos de suas lagoas na Carolina do Norte (um dos maiores desastres ambientais dos EUA) e como resultado, pagou uma multa de 12,6 milhões de dólares, o mesmo valor que a empresa lucrava a cada 10 horas à época (TIETZ, 2006).
} 
Rev. Interd. em Cult. e Soc. (RICS), São Luís, v. 6, n. 2, p. 174-194, jul./dez. 2020 ISSN eletrônico: $2447-6498$

do boi" no Brasil) e é alimentado pelo grande poder econômico que essas corporações passaram a exercer a partir da Revolução Verde, na segunda metade do século XX. Nos anos 1980 e 1990, esse poder intensifica-se com o processo de verticalização do setor, ocasionando com que, atualmente, apenas 87 corporações com sede em 30 países controlem várias ou todas as etapas da cadeia produtiva do agronegócio em todo o planeta (PINA, 2018).

Esse pequeno número de corporações detentoras do controle da produção mundial de carne formam o chamado Complexo Global da Carne, "uma rede de empresas altamente concentrada, horizontal e verticalmente integrada que controla os insumos, a produção e o processamento de um amplo número de animais" (SANTOS, M e GLASS, V., 2018, p. 32). O processo de expansão dessas empresas passa pela pressão de mercado exercida junto aos pequenos produtores, que, sem condições de concorrer com as grandes indústrias, acabam por se integrar ao seu sistema produtivo ou por vender suas propriedades. O resultado desse domínio do mercado global é que a maior parte de carne consumida atualmente no mundo advém, portanto, do sistema intensivo de confinamento de animais ${ }^{21}$.

Mesmo que o consumo excessivo de produtos de origem animal (especialmente na forma processada) seja comprovadamente nocivo à saúde, ainda é comum vermos o lobby das corporações de carne e laticínios atuando junto aos organismos nacionais de saúde na tentativa de levar seus produtos a parcelas cada vez maiores da população, nas mais diferentes realidades do mundo. Aqui chegamos a um ponto importante da reflexão que estamos construindo: apesar de presente praticamente no mundo inteiro, alimentos advindos do sistema industrial - como os que têm origem no confinamento intensivo de animais e os produtos processados e ultraprocessados em geral - são consumidos de formas distintas pelos diferentes grupos populacionais, nos exigindo, assim, uma análise interseccional, que considere, além dos aspectos de classe e renda, fatores como idade, gênero e raça. Intercruzando esses elementos, podemos chegar a análises mais aprofundadas sobre as formas pelas quais a alimentação é experienciada pelos sujeitos em diferentes recortes espaciais e sociais. Acreditamos que é fundamental associar questões subjetivas que incidem nas escolhas alimentares às questões materiais de acessos aos alimentos para, assim, compreendermos por que certos tipos de alimentos são mais consumidos por determinadas parcelas da população e quais as consequências desse consumo para sua saúde.

\footnotetext{
${ }^{21}$ Nos Estados Unidos, país em que mais se consome carne per capta no mundo, cerca de 70,4\% das vacas, 98,3\% dos porcos, $99,8 \%$ dos perus e $99,9 \%$ dos frangos são criados em fazendas industriais (USDA Census of Agriculture de 2017).
} 
Rev. Interd. em Cult. e Soc. (RICS), São Luís, v. 6, n. 2, p. 174-194, jul./dez. 2020

ISSN eletrônico: $2447-6498$

\section{UM SISTEMA ALIMENTAR QUE NÃO SUSTENTA OS CORPOS. MAS QUAIS CORPOS?}

O sistema alimentar industrial é um sistema de produção e danos intensivos. A capacidade de fornecer cada vez mais alimentos em grande escala e, por isso, a baixos preços, tem um preço alto para o meio ambiente, como vimos, e também para a saúde das pessoas. Estudos como o Global Burden Disease (GBD, 2019) comprovam a relação entre consumo de carne e alimentos ultraprocessados e diversas doenças, em especial as doenças crônicas não transmissíveis (DCNT), como doenças cardiovasculares, hipertensão arterial, diabetes, câncer e doenças respiratórias crônicas. Atualmente, as DCNT lideram as causas de mortes geral e prematuras no mundo, respondendo por $71 \%$ do total (OPAS BRASIL, 2018), e por $72 \%$ das mortes no Brasil (MALTA, D. C. et al, 2019). Dessa forma, ao mesmo tempo em que vivemos mais (a expectativa de vida média no mundo passou de 46 anos em 1950 para 72 anos em 2020, segundo dados da ONU), vivemos, também, mais doentes.

Assim o atual sistema alimentar industrial adoece e mata paisagens e corpos em todo o mundo, sendo responsável pela contradição cada vez mais comum de populações ao mesmo tempo obesas e desnutridas (SOUZA, N, P. et al, 2017), que, em face a insegurança alimentar que vivenciam, consomem alimentos de baixa qualidade nutricional, mais acessíveis tanto quanto ao preço quanto à disponibilidade espacial. Sua dominação na alimentação da população, apoiada por setores governamentais e por uma massiva propaganda, cresce com o aumento da urbanização, da intensificação dos fluxos globais das empresas e de suas marcas e com as mudanças culturais nas relações de trabalho e ritmos de vida, que exigem cada vez mais longas horas fora da residência.

Com a expansão do sistema alimentar industrial, ocorreu uma progressiva mudança no padrão alimentar mundial e no brasileiro, destacando-se, dentre essas mudanças, o aumento do consumo de produtos de origem animal, como falamos anteriormente, e o aumento do consumo de açúcar, adicionado aos produtos ultraprocessados ${ }^{22}$ em geral. Embora sejam os países de maior renda os principais consumidores de ultraprocessados em termos de volume, o que vem se observando é o elevado ritmo de crescimento do consumo desses produtos nos países de renda mais baixa. O relatório "Alimentos e bebidas ultraprocessados na América Latina: tendências, efeito na obesidade e implicações para políticas públicas", publicado em 2018 pela Organização Pan-Americana de Saúde (OPAS), aponta que, enquanto o

\footnotetext{
22 Produtos ultraprocessados são formulações industriais elaboradas a partir de substâncias derivadas dos alimentos ou sintetizadas de outras fontes orgânicas. Como exemplos, podemos citar os produtos tipo snack em pacote; margarinas; refrigerantes, bebidas açucaradas à base de leite, fast-foods e "comidas prontas", reconstituídos e pré-preparados de carne, peixe e frutos do mar, vegetais ou queijo, etc. (OPAS, 2018. p. 6)
} 
Rev. Interd. em Cult. e Soc. (RICS), São Luís, v. 6, n. 2, p. 174-194, jul./dez. 2020

ISSN eletrônico: 2447-6498

crescimento do consumo de ultraprocessados na América do Norte foi de 2,3\% entre os anos de 2000 a 2013, na América Latina, esse número foi de 48\% no mesmo período, superando a média global de 43.7\% (OPAS, 2018, p. 16).

No caso específico do Brasil, a transição no padrão alimentar da população vem sendo caracterizada nas últimas décadas por uma maior ingestão de gorduras em geral, gorduras de origem animal e açúcar, e pela diminuição no consumo de cereais e leguminosas - o que resultou, por um lado, no aumento na disponibilidade de calorias per capita e, por outro, no aumento da obesidade e das DCNT (BARRETO, S. M. et al, 2005. p. 44). Nos últimos anos, o consumo de alimentos ultraprocessados continuou a crescer no Brasil, porém em um ritmo mais lento, mas a queda no consumo de leguminosas como feijão $(-52 \%)$ e de cereais como arroz (-37\%) manteve-se no país, de acordo com a Pesquisa de Orçamentos Familiares 2017 2018, publicada pelo IBGE.

Muitos especialistas consideram esse atual padrão alimentar e nutricional como o principal fator responsável pela epidemia mundial de doenças crônicas não transmissíveis. No entanto, a partir dos dados trazidos anteriormente, podemos notar que essa epidemia se faz mais presente e tem mais impactos em determinados recortes econômicos e espaciais. Esses recortes nos trazem aspectos muito relevantes a respeito das desigualdades alimentares e de saúde e da sua relação com o sistema capitalista.

Vejamos um exemplo de como o fator renda incide nas características alimentares em diferentes contextos: apesar de os produtos ultraprocessados serem relativamente acessíveis, no Brasil, seu consumo ainda não é generalizado como nos países do norte global - para termos uma ideia, no Reino Unido, a participação desses produtos na alimentação das famílias pode chegar a 50\% do total (BOSELEY, S, 2018). Analisando a realidade brasileira, existe uma significativa diferença entre o consumo desses produtos pelas classes de maior e menor rendimento: as primeiras chegam a consumir quase sete vezes mais alimentos preparados e misturas industriais do que as últimas (IBGE, 2020). No entanto, apesar de acometerem indivíduos de todas as camadas socioeconômicas, as DCNT atingem de forma mais intensa exatamente os grupos de menor renda e baixa escolaridade, agravando ainda mais a sua situação de vulnerabilidade (MALTA, D. C. et al, 2019, p. 2).

Ao considerarmos a população com o mínimo de escolha alimentar, outros aspectos além da renda incidem nas características da sua alimentação, tais como aspectos culturais e fatores de idade, raça, gênero e localização. No Brasil, por exemplo, a participação dos alimentos in natura ou minimamente processados no total calórico da disponibilidade alimentar dos domicílios é maior nas regiões Norte e Nordeste (58,2\% e 54,5\% 
Rev. Interd. em Cult. e Soc. (RICS), São Luís, v. 6, n. 2, p. 174-194, jul./dez. 2020

ISSN eletrônico: $2447-6498$

respectivamente), o que indica uma maior preservação dos hábitos alimentares locais, como o consumo de farinha de milho e mandioca, fubá, feijão e peixes. Já o fator geracional na alimentação vem chamando a atenção dos especialistas devido à tendência mundial de aumento da obesidade entre as crianças e adolescentes: nas últimas quatro décadas, esse número aumentou dez vezes, o que pode ser explicado por uma maior suscetibilidade desse grupo ao consumo de alimentos baratos, ultraprocessados e densos em calorias. O aumento das taxas de obesidade infantil vem ocorrendo de forma mais intensa nos países de baixa e média renda, tendo se estabilizado nos países de renda mais elevada (OPAS BRASIL, 2017).

Já a relação entre raça e alimentação vem sendo analisada por diversas(os) pesquisadoras(es) no mundo, sendo uma das questões abordadas nesses estudos o padrão alimentar de populações negras em países como os Estados Unidos (HARPER, 2009; BOWER, 2013). De forma geral, esses trabalhos alertam para o alto consumo de alimentos de origem animal e produtos ultraprocessados por parte dessas populações, que tem como causa tanto fatores de renda quanto questões culturais e que incide no grande número de casos de DCTN nessas populações. As(os) autoras(es) denunciam a falta de acesso a alimentos naturais em comunidades e bairros negros nas cidades norte-americanas, que resulta na formação dos chamados desertos alimentares.

A ocorrência dos desertos alimentares não é uma realidade muito distinta da que acontece nos principais centros urbanos brasileiros (CAISAN, 2019). No Brasil, vem se ampliado o número de pesquisas que demonstram como a aliança entre fatores espaciais, de classe e raça incidem nos diferentes comportamentos alimentares dos grupos populacionais, sendo as populações negras e de menor rendimento, moradoras das periferias, as mais afetadas pela falta de acesso a alimentos naturais e, consequentemente, pela ocorrência de doenças crônicas, o que alguns estudiosos e ativistas denominam como nutrícídio dessas populações (AFRIKA, L. O., 1994).

No Brasil, o consumo de alimentos naturais e de melhor qualidade nutricional é um privilégio de classe: famílias com rendimento superior a 14 mil reais consomem em média 187\% mais hortaliças e $313 \%$ mais frutas que as famílias com rendimentos inferiores a dois mil reais (IBGE, 2020). Essa discrepância ocorre não apenas pelo acesso mais facilitado a feiras orgânicas, mercados e restaurantes naturais, mas também pelo acesso ao conhecimento sobre importância do consumo desses alimentos e, da mesma forma, dos malefícios do consumo excessivo de carnes e produtos ultraprocessados. Espacialmente, esse privilégio materializa-se e dá origem a paisagens alimentares (foodscapes) distintas daquelas encontradas nas periferias, nas quais predominam grandes redes de supermercados e pequenos 
Rev. Interd. em Cult. e Soc. (RICS), São Luís, v. 6, n. 2, p. 174-194, jul./dez. 2020

ISSN eletrônico: $2447-6498$

mercados com ampla oferta de produtos processados e ultraprocessados e pouca ou nenhuma oferta de produtos naturais e sem agrotóxicos (MACKENDRICK, N., 2014).

As diferentes escolhas alimentares (quando existentes) também são influenciadas pelo fator gênero: em todo o mundo, a maioria da população que não faz uso de produtos de origem animal para a alimentação é formada por mulheres, e em alguns países esse percentual chega a $75 \% \%^{23}$. Questões culturais repercutem na forma que o simbolismo da carne é significado por homens e mulheres, existindo diversos estudos voltados para a análise da relação entre consumo de carne e o machismo em uma sociedade patriarcal (ADAMS, C. J.; SANTOS, P., 2019). De forma geral, esses estudos evidenciam a forte associação entre masculinidade/virilidade e consumo de carne, da mesma forma que explicitam os mecanismos de naturalização do consumo de alimentos mais leves pelas mulheres ${ }^{24}$, em decorrência dos mecanismos de controle do corpo feminino.

Como último exemplo dessa análise interseccional da alimentação, outros estudos abordam os fatores que incidem na alimentação de mulheres negras e como ela se diferencia da alimentação de mulheres brancas, a partir de uma complexa relação entre fatores como classe e racismo na construção social do padrão do corpo da mulher negra e da mulher branca. No documentário The Invisible Vegan (LEVYA, 2019) e no livro Sistha Vegan (HARPER, 2009), as autoras demonstram como o veganismo foi associado às mulheres brancas ${ }^{25}$ e a um padrão elitizado de estilo de vida saudável, que excluiria do seu imaginário social, portanto, homens e mulheres negras. Essas mesmas autoras, assim como outras ativistas nos Estados Unidos e no Brasil ${ }^{26}$, estão construindo uma nova forma de entendimento de alimentação saudável e acessível a partir do resgate da ancestralidade e dos hábitos alimentares do continente africano - majoritariamente de base vegetal - , buscando se desvincular dos alimentos associados e consumidos pelas populações negras durante a escravidão.

\section{COMO UNIR TODAS ESSAS QUESTÕeS: O ELO AgROECOLÓGICO E AS CONTRIBUIÇÕES DA GEOGRAFIA E DAS CIÊNCIAS HUMANAS}

Todas as questões abordadas nesse artigo, apesar de aparentemente distintas em termos de escalas e tema de abordagem (meio ambiente, saúde, pandemias, raça e gênero), estão, na verdade, intimamente conectadas e articuladas a partir do ato da alimentação. Dessa

\footnotetext{
${ }^{23}$ GORVETT, Zarin, The mystery of why there are more women vegans. BBC 18/02/020.

${ }^{24}$ Como exemplo, no Brasil, a frequência de consumo regular de frutas e hortaliças pela população em 2017 foi de $18,4 \%$ entre os homens e $27,2 \%$ pelas mulheres. (VIGITEL BRASIL 2019)

${ }^{25}$ Nos Estados Unidos, $54 \%$ da população que se declara vegetariana é branca, enquanto $7 \%$ são negros (MILLUM, Joseph.. Who Are The Vegetarians? Faunalytics, 20/06/2018.

${ }^{26}$ No Brasil, o Movimento Afro Vegano (MAV) é um importante difusor dessas ideias nas redes sociais.
} 
Rev. Interd. em Cult. e Soc. (RICS), São Luís, v. 6, n. 2, p. 174-194, jul./dez. 2020

ISSN eletrônico: $2447-6498$

maneira, buscamos ao longo desse trabalho evidenciar a importância da alimentação para as pesquisas e estudos que se desenvolverão no mundo pós-pandêmico (mais particularmente, na área da geografia), assim como buscamos entendê-la como fator crucial para as mudanças desejadas e/ou para as que serão necessárias à nossa existência no planeta. Compreender toda a rede que envolve as escolhas dos alimentos e as suas consequências é ponto incontornável se quisermos olhar seriamente para as questões ambientais e sanitárias em escala global. É preciso ter todos esses fatores em consideração se quisermos, de fato, pensar não apenas a partir da geografia, mas também de outras áreas, os caminhos a serem trilhados em direção às mudanças possíveis.

Acreditamos que essas mudanças exigem uma inversão no alcance e no papel que os atuais sistemas alimentares exercem na alimentação em escala global e local. Se o que temos hoje é o predomínio e o crescimento do sistema alimentar industrial, devemos caminhar em direção ao fortalecimento dos sistemas alimentares tradicionais, especialmente através da agroecologia. Apesar da opção por uma alimentação com base em produtos agroecológicos ainda passar por uma questão de privilégio e escolha, em algumas décadas, essa ação será parte de um conjunto de mudanças que deverão ser adotadas pela maioria da população mundial para o seu próprio abastecimento, assim como para a manutenção do planeta ${ }^{27}$. Essa transição, sabidamente, não é fácil e envolve diversas questões e interesses que atingem diretamente as estruturas de produção capitalistas. Os desafios para tanto podem ser divididos em dois pontos principais, mais comumente pautados: teria o sistema agroecológico capacidade de alimentar uma população mundial que poderá chegar a 10 bilhões de pessoas nas próximas décadas? E como fazer esse sistema acessível para a maior parte da população mundial?

Para respondermos essas questões, primeiramente é importante traçarmos algumas considerações a respeito da agroecologia. Diferentemente do que pode perpassar o imaginário comum, os produtos agroecológicos não são apenas produtos orgânicos, ou seja, livres do uso de agrotóxicos. Sendo o Brasil um dos países líderes na liberação de agrotóxicos no mundo, vem aumentando nos últimos anos a demanda por produtos orgânicos nas prateleiras dos mercados e nas feiras nas cidades. No entanto, os produtos orgânicos vendidos nos supermercados (e que apresentam selo de certificação) chegam aos consumidores com preços elevados, o que os torna inacessíveis para uma grande parcela da população.

${ }^{27}$ REUTERS. Pode faltar alimento para abastecer população mundial até 2050, diz ONU. G1, 28/11/2011; WORLD RESOURCES INSTITUTE. Creating A Sustainable Food Future. Synthesis Report, Dezembro, 2018. 
Rev. Interd. em Cult. e Soc. (RICS), São Luís, v. 6, n. 2, p. 174-194, jul./dez. 2020

ISSN eletrônico: 2447-6498

Além de oferecer produtos livres de agrotóxicos (em alguns casos, não-certificados, devido às dificuldades dos critérios e aos custos para obtenção do selo orgânico), a agroecologia baseia-se em uma estrutura de produção distinta, quanto à origem do produto, o papel dos(as) agricultor(as) e à cadeia de comercialização (com menos intermediários). A agroecologia tem forte vínculo com a valorização dos saberes tradicionais e com a defesa de reforma agrária e da agricultura familiar, propondo, dessa maneira, um sistema alimentar mais sustentável ambientalmente e mais justo não apenas para quem compra, mas também para quem produz o alimento.

Do outro lado, muitos defensores do agronegócio afirmam que ele desempenha papel fundamental para a alimentação do planeta e sem ele seria impossível alimentar a população mundial - quando muitos estudos mostram o contrário ${ }^{28}$. Sim, a agricultura sustentável pode alimentar a população global, mas, para tanto, é necessário que haja uma mudança no padrão alimentar mundial, que passe, obrigatoriamente, pela redução do consumo de carne.

Considerando a realidade de países com grande desigualdade social, como é o caso do Brasil, como tornar o acesso aos produtos agroecológicos possível para toda população e não apenas para a classe média e alta com acesso a conhecimento e moradora dos bairros mais nobres e centrais nas cidades? Como trabalhar para desfazer a ideia - criada a partir de fatos materiais - de que produtos sem agrotóxicos são um privilégio para poucos ou, em outras palavras, um nicho do mercado de saúde? Como promover uma mudança nos atuais hábitos alimentares no Brasil e no mundo freando o consumo de produtos ultraprocessados sem valor nutricional e cuja produção é dominada por um pequeno grupo de empresas transnacionais?

Articular as escalas que vão do consumo individual de alimentos até uma crise sanitária global como a que estamos vivendo se faz necessário para mudarmos essa situação. Proporcionar o acesso a produtos vegetais livres de veneno a todos(as) passa pela vontade política e por um trabalho de informação, acesso e promoção de políticas públicas para a agricultura familiar, para que seus produtos cheguem com menores preços a todas as áreas das cidades. Outro caminho é trabalhar para a redução/extinção dos desertos alimentares nas periferias urbanas, promovendo a disponibilidade de produtos naturais de fácil alcance através de projetos como as hortas comunitárias, por exemplo. Mas, para que as populações entendam a importância dessa mudança alimentar para si mesmas e para o planeta, um grande e delicado trabalho precisa ser construído, em parceria com essas populações e baseado em suas vivências.

\footnotetext{
${ }^{28}$ UNCTASD. Trade And Environment Review 2013.; REGANOLD, J., WACHTER, J. Organic agriculture
} in the twenty-first century. Nature Plants 2, 15221 (2016). 
Rev. Interd. em Cult. e Soc. (RICS), São Luís, v. 6, n. 2, p. 174-194, jul./dez. 2020

ISSN eletrônico: $2447-6498$

Consideramos que professores(as) e pesquisadores(as) da geografia podem desenvolver um papel importante, visto que sua atuação permeia várias das questões abordadas - em especial as de interface ambiental, agrária e populacional. O trabalho com comunidades, periferias, assentamentos rurais, pequenos agricultores e nas escolas e universidades encontra amplo campo e possibilidades de ação. No entanto, é importante ressaltar que esse trabalho não deve ser apenas o de "levar" informação, "de cima para baixo". E aqui voltamos aos aspectos subjetivos e culturais que permeiam os hábitos alimentares sem considerá-los, isto é, sem uma construção (prática e teórica) interseccional e intersubjetiva, dificilmente essa proposta alcançará êxito e proporcionará condições que levem as pessoas a refletir sobre os desejos, significados e consequências de seus hábitos alimentares.

A questão que fica é se nós, professores(as) e pesquisadores(as) das ciências humanas em geral estamos realmente dispostos(as) a desconstruir práticas estruturais e pessoais para a construção de alternativas ao panorama que se delineia, no qual as pandemias serão cada vez mais recorrentes. Quais contribuições podemos oferecer à sociedade e à ciência na busca por mudanças nesse cenário, junto às populações, aos(às) estudantes e aos(às) trabalhadores(as)? Quanto podemos e - de fato- queremos trabalhar no combate a um sistema alimentar que não apenas promove desigualdades e privilégios em termos nutricionais, mas também assimetrias em todas as outras etapas da sua produção e cujas piores consequências aumentam à medida em que se acumulam recortes de classe, raça e gênero? Não à toa as maiores vítimas tanto do nutrícídio contemporâneo quanto da pandemia do novo coronavírus são as populações pobres e não brancas ${ }^{29}$, o que demonstra mais uma vez como os processos que envolvem a alimentação estão articulados.

Consideramos que todos(as) que possuem escolhas alimentares temos parte e podemos agir nessa questão. Está no hábito de comer, diário, essencial (por vezes praticado de forma automática e carente de reflexões que embasem a sua construção enquanto ação política) parte importante da mudança que precisamos para a construção de alternativas a um mundo marcado por pandemias e desigualdades de todos os tipos. Acreditamos que a Geografia e as demais ciências humanas não podem desviar dessas questões, devendo, mais do que nunca, enfrentá-las a partir da contribuição teórica e das ações práticas de seus(suas) profissionais.

\footnotetext{
${ }^{29}$ SOARES, Marcelo. Dados do sus revelam vítima-padrão de covid-19 no Brasil: homem, pobre e negro. Época. 03/07/2020; AGÊNCIA ESTADO. Negros e latinos enfrentam taxas altas de infecção nos EUA. A Gazeta. 04/04/2020
} 
Rev. Interd. em Cult. e Soc. (RICS), São Luís, v. 6, n. 2, p. 174-194, jul./dez. 2020

ISSN eletrônico: 2447-6498

\section{REFERENCIAS}

ADAMS, Carol J. A política sexual da carne: uma teoria feminista-vegetariana. Editora Alaude. 2018

AFRIKA, Llaila O. Nutricide : the nutricional destruction of the Black race. A\&B Publishiers Group : New York, 1994.

AGENCIA EFE. Agricultura e pecuária são atividades primárias que mais contaminam a água. G1. 04/05/2018. Disponível em: https://cutt.ly/Nfz1GNJ Acesso em: 27/09/2020.

ARNAIZ, Mabel Gracia. Mudanças econômicas e socioculturais e o sistema alimentar em direção a uma nova ordem alimentar? In: CANESQUI, AM., e GARCIA, RWD. (orgs). Antropologia e nutrição: um diálogo possível [online]. Rio de Janeiro: Editora FIOCRUZ, 2005. P. $147-164$.

BARIFOUSE, Rafael. Como o Brasil foi afetado pela pandemia de H1N1, a $1^{\text {a }}$ do século 21 ? BBC News Brasil. 25/03/2020. Disponível em: https://cutt.ly/Ffcks30 Acesso em: 27/09/2020.

BARRETO, Sandhi Maria et al. Análise da estratégia global para alimentação, atividade física e saúde, da Organização Mundial da Saúde. Epidemiologia e Serviços da Saúde, Brasília, v. 14, n. 1, p. 41-68, mar. 2005.

BOSELEY, Sarah. 'Ultraprocessed' products now half of all UK family food purchases. The Guardian, 02/02/2018. Disponível em : https://cutt.ly/hfz1GoR Acesso em: 27/09/2020.

BOWER, Kelly $\mathrm{M}$ et al. "The intersection of neighborhood racial segregation, poverty, and urbanicity and its impact on food store availability in the United States." Preventive medicine vol. 58 (2014): 33-9.

CAISAN (Câmara Interministerial de Segurança Alimentar e Nutricional). Mapeamento dos Desertos Alimentares no Brasil. Ministério do Desenvolvimento Social/MDS. 2018.

DA SILVA, V. P. et al, Uma medida de sustentabilidade ambiental: Pegada hídrica. Revista Brasileira de Engenharia Agrícola e Ambiental v.17, n.1, p.100-105, 2013.

DOVE, Rick. I saw Florence sending millions of gallons of animal poop flooding across North Carolina. The Whashington Post. September 22, 2018. Disponível em: https://cutt.ly/rfz1FGh Acesso em: 27/09/2020.

DUTKIEWICZ, Jan, TAYLOR, Astra e VETTESE, Troy. The Covid19 pandemic shows we must transform the global food system. The Guardian. 16/04/2020. Disponível em: https://cutt.ly/ffz1DM0 Acesso em: 27/09/2020.

FAO. World Livestock 2013 - Changing disease landscapes. Rome, 2013.

GLOBO RURAL 'Frango 4.0': conheça o condomínio de granjas que produz 7 milhões de aves por ano. 19/05/2019. Disponível em: https://cutt.ly/jfz1Dcs Acesso em: 27/09/2020. 
Rev. Interd. em Cult. e Soc. (RICS), São Luís, v. 6, n. 2, p. 174-194, jul./dez. 2020 ISSN eletrônico: $2447-6498$

GBD 2017 DIET COLLABORATORS*. Health effects of dietary risks in 195 countries, 1990-2017: a systematic analysis forthe Global Burden of Disease Study 2017. Lancet, 2019; 393: $1958-72$.

GODFRAY ET AL. Meat consumption, health, and the environment . Science 361, 243 (2018) 20 de Julho de 2018.

HARPER, A. B. Sistah Vegan: Black Female Vegans Speak on Food, Identity, Health, and Society, Editora: Lantern Books, 2009.

HLPE, 2014. Food losses and waste in the context of sustainable food systems. A report by the High Level Panel of Experts on Food Security and Nutrition of the Committee on World Food Security, Rome 2014.

KRISTOF, Nicholas. Our Pigs, OurFood, Our Healt. The New York Times. 11/03/2009. Disponível em: https://cutt.ly/yf1nR5V Acesso em: 27/09/2020.

IBGE. Pesquisa de orçamentos familiares 2017-2018: avaliação nutricional da disponibilidade domiciliar de alimentos no Brasil / IBGE, Coordenação de Trabalho e Rendimento. Rio de Janeiro: IBGE, 2020. 61 p.

LEYVA, Jasmine. The Invisble Vegan. 2019 (documentário)

MACKENDRICK, Nirah. Foodscape. Context, 2014.

MALTA, D. C. et al. Probabilidade de morte prematura por doenças crônicas não transmissíveis, Brasil e regiões, projeções para 2025. Revista Brasileira de Epidemiologia. 2019; 22: E190030.

MENEZES, Maíra. Fiocruz identifica nova variante do vírus influenza no Brasil. Portal FIOCRUZ, 13/07/2020. Disponível em : https://cutt.ly/efz1SL8 Acesso em: 27/09/2020.

DW. Fome se alastra pelo mundo, diz relatório da ONU. 15/07/2019. Disponível em: https://cutt.ly/ff1nJGX Acesso em: 27/09/2020.

NAÇÕES UNIDAS BRASIL. ARTIGO: Já existem mais obesos que famintos. 20/02/2020. Disponível em: https://cutt.ly/Vf1n3TN Acesso em: 27/09/2020.

OPAS. Alimentos e bebidas ultraprocessados na américa latina: tendências, efeito na obesidade e implicações para políticas públicas. Brasília, DF: OPAS; 2018.

OPAS BRASIL. Obesidade entre crianças e adolescentes aumentou dez vezes em quatro décadas, revela novo estudo do Imperial College London e da OMS. 10/10/2017. Disponível em: https://cutt.ly/afz1OHh Acesso em: 27/09/2020.

OPAS BRASIL. Comissão da OMS pede ação urgente contra doenças crônicas não transmissíveis. 01/06/2018. Disponível em: https://cutt.ly/Ofz1PJn Acesso em: 27/09/2020.

OUR WORLD IN DATA: Research and data to make progress against the world's largest problems. 2020. Disponível em: https://ourworldindata.org/Acesso em: 27/09/2020. 
Rev. Interd. em Cult. e Soc. (RICS), São Luís, v. 6, n. 2, p. 174-194, jul./dez. 2020 ISSN eletrônico: $2447-6498$

PAIM, C. S. e ALONSO, W. Pandemias, saúde global e escolhas pessoais. Cria Editora: Alfenas, 2020.

PINA, Rute. Só 87 empresas controlam a cadeia produtiva do agronegócio. Brasil de Fato | São Paulo/ 04/09/2018. Disponível em: https://cutt.ly/yfz1AkG Acesso em: 27/09/2020.

SANTOS, Maureen, GLASS, Verena (orgs). Altas do agronegócio: fatos e números sobre as corporações que controlam o que comemos.- Rio de Janeiro : Fundação Heinrich Böll, 2018.

SANTOS, Patrícia L. dos. Relações interseccionais em rede: feminismos, animalismos e veganismos. $1^{\text {a }}$ edição. Editora Devires: Salvador, 2019.

SILVA C. L, BASSI N. S. S. Análise dos impactos ambientais no Oeste Catarinense e das tecnologias desenvolvidas pela Embrapa Suínos e Aves. Informe Gepec. Toledo, v. 16, nº 1 , p. 128-143, 2012.

SOUZA, N, P. et al. A (des)nutrição e o novo padrão epidemiológico em um contexto de desenvolvimento e desigualdades Ciência \& Saúde Coletiva, 22(7):2257-2266, 2017.

TIETZ, Jeff. Boss Hog: The Dark Side of America's Top Pork Producer. Rolling Stones. 14/12/2006. Disponível em: https://cutt.ly/pfz1HxU Acesso em: 27/09/2020.

THORNTON, Alex. This is how many animals we eat each year. World Economic Forum. 08 Feb 2019. Disponível em : https://cutt.ly/Nfz1HJZ Acesso em: 27/09/2020.

VIGITEL BRASIL 2018.Vigilância de fatores de risco e proteção para doenças crônicas por inquérito telefônico. Brasília: Ministério da Saúde, 2019.

WALLACE, Arturo. Coronavírus: como foram controladas as epidemias de Sars e Mers (e no que elas se diferenciam da atual). BBC News Mundo. 31/05/2020. Disponível em: https://cutt.ly/Gfz1Jkn Acesso em: 27/09/2020.

WHO. Bulletin of the World Healph Organization. April 2004, 82 (4).

XIAO, K., ZHAI, J., FENG, Y. et al. Isolation of SARS-CoV-2-related coronavirus from Malayan pangolins. Nature 583, 286-289 (2020). 